\title{
A BEHAVIORAL MODEL FOR MEASURING UNIVERSITY CLIMATE ENTREPRENEURSHIP SEBAGAI SALAH SATU SOLUSI KESEJAHTERAAN KELUARGA DI SURABAYA
}

\author{
Christina Esti Susanti \\ Universitas Katolik Widya Mandala Surabaya
}

This study uses a model of behavior that involves the integration of individuals, organizations, and institutions as determinant factors and their effects on academic entrepreneurial behavior. In a comprehensive model of behavior puts academic entrepreneurial intention as intervening varible that affect academic entrepreneurial behavior. Academic entrepreneurial intentions are directly affected by the perceived desirability, perceived feasibility, and innovation values fit. And these variables indirectly affect academic entrepreneurial behavior. This behavioral model using Structural Equation Modeling (SEM) as a tool to test the statistical test that the institutional environment which will positively affect mempengarruhi individual entrepreneurial intentions among members of the university community as a solution to the welfare of the family. The results of this study prove that all proposed hypothesis is accepted.

Keywords:

perceived desirability, perceived feasibility, innovation values fit, academic entrepreneurial intention, and academic entrepreneurial behavior 


\section{PENDAHULUAN}

\subsection{Latar Belakang}

Permasalahan bangsa Indonesia saat ini begitu kompleks, hampir dari semua aspek kehidupan menjadi masalah nasional. Jumlah pengangguran dari tahun ke tahun terus meningkat, hal ini disebabkan sedikitnya lapangan pekerjaan sedangkan jumlah lulusan sekolah menengah dan perguruan tinggi terus bertambah. Akibatnya terjadi ketidakseimbangan antara jumlah lapangan pekerjaan dengan orang yang akan bekerja. Apalagi diperparah dengan timbulnya aksi PHK dari beberapa perusahaan yang mengalami kebangkrutan. Masalah pengangguran sebenarnya bisa diatasi jikalau Negara mampu menyediakan lapangan pekerjaan sebanyak mungkin. Namun hal ini sepertinya tidak mungkin bisa secepatnya terealisasi, karena banyaknya kendala baik dari segi ekonomi maupun sumber daya manusia (SDM) itu sendiri.

Hidayat mengemukakan bahwa berdasarkan data Badan Pusat Statistik di Tahun 2005, tercatat tingkat pengangguran di Indonesia sekitar 11 juta orang”. Mengingat betapa banyaknya jumlah pengangguran di Indonesia saat ini, maka mahasiswa jurusan manajemen dan akuntansi diharapkan tidak hanya mengandalkan bekerja di sektor pemerintahan atau bekerja untuk mengisi lowongan kerja, tetapi juga diharapkan mampu untuk memanfaatkan ilmu yang telah dimiliki. Dan dapat memanfaatkan peluang yang ada sebagai usaha untuk kerja mandiri.

Akan tetapi penyebab dari kurangnya minat dalam wirausaha adalah pandangan negatif dari sebagian masyarakat. Sebagian orang tua tidak menginginkan anak-anaknya menerjuni bidang ini, dan berusaha mengalihkan perhatian anak untuk menjadi pegawai baik negeri dan swasta, apalagi bila anaknya sudah bertitel lulus perguruan tinggi. Pandangan tersebut sudah berkesan jauh di lubuk hati sebagian besar rakyat. Landasan filosofis inilah yang menyebabkan rakyat Indonesia tidak termotivasi terjun ke dunia bisnis.

Selain kondisi tersebut, hasil survey sosial ekonomi nasional oleh BPS (http://www.ditkelembagaan) Maret 2006 menyebutkan bahwa jumlah penduduk miskin di Indonesia pada Maret 2006 sebanyak 39,05 juta jiwa atau 17,75 persen dari total 222 juta jiwa penduduk. Bahkan mereka yang lulus perguruan tinggi semakin sulit mendapatkan pekerjaan karena tidak banyak terjadi ekspansi kegiatan usaha. Dalam keadaan seperti ini maka masalah pengangguran termasuk yang berpendidikan tinggi akan berdampak negatif terhadap stabilitas sosial dan kemasyarakatan.

Kondisi tersebut didukung pula oleh kenyataan bahwa sebagian besar lulusan perguruan tinggi adalah lebih sebagai pencari kerja (job seeker) daripada pencipta lapangan pekerjaan (job creator). Hal ini bisa jadi disebabkan karena system pembelajaran yang diterapkan di berbagai perguruan tinggi saat ini lebih terfokus pada bagaimana menyiapkan para mahasiswa yang cepat lulus dan mendapatkan pekerjaan, bukannya lulusan yang siap menciptakan pekerjaan. Di samping itu, aktivitas kewirausahaan (entrepreneurial activity) yang relatif masih rendah.

Di era Globalisasi dan pertumbuhan ekonomi yang cukup pesat ini, mahasiswa merupakan potensi pembangunan, baik dalam jumlah maupun mutu lulusan itu sendiri. Beberapa penelitian menunjukkan bahwa faktor pendorong pertumbuhan ekonomi yang pesat adalah faktor manusianya. Sekarang ini kita menghadapi kenyataan bahwa jumlah sarjana Indonesia masih banyak yang menganggur dan mutunya belum dikatakan maksimal. Idealnya seorang mahasiswa harus lebih 
dimotivasi oleh adanya keinginan berwirausaha dari pada hanya sekedar mencari lowongan pekerjaan sematamata. Ia tidak cepat mudah putus asa karena gagal bekerja, tetapi selalu mencari cara dan mengasah kreativitas keahlian yang dipunyainya.

Di era otonomi daerah saat ini, pendidikan kewirausahaan sangat dibutuhkan. Karena, dengan pendidikan tersebut sebenarnya akan banyak menciptakan pengusaha-pengusaha baru. Tak hanya penting, tetapi sangat mendesak. Maka sebaiknya, iklim menekuni dunia usaha harus diciptakan. Sehingga, perlu ada solusi, yaitu bagaimana membuat pendidikan untuk menciptakan orang jadi pengusaha. Hal itu biasa diberikan lewat model pendidikan, yang bukan saja mengandalkan pada pengetahuan, tetapi juga emosional. Termasuk bagaimana mencerdaskan emosi.

Pemahaman kewirausahaan harus dimiliki oleh mahasiswa karena mahasiswa sebagai penerus bangsa diharapkan mampu menjadi tulang punggung negara. Sehingga dengan hasil pendidikan yang dikuasainya mampu menciptakan lapangan kerja, bukan menambah jumlah pengangguran setelah ia lulus dari sebuah perguruan tinggi dan diharapkan mampu bekerja dengan baik, dilihat dari segi ilmu maupun teknis lapangan. Jadi, sebisa mungkin seorang mahasiswa dituntut untuk berpikir secara kreatif terhadap peluang bisnis yang ada di masyarakat dan berani mencoba untuk memulai usaha.

\subsection{Perumusan Masalah}

Universitas adalah sumber terbesar pengetahuan khususnya informasi ekonomi dalam pandangan ekonomi global. Lembaga akademis menggunakan sumber-sumber pemerintah dan mengorganisasikannya ke dalam aktivitas-aktivitas melalui kesempatan-kesempatan yang diciptakan oleh informasi ekonomi yang dimilikinya. Untuk mengembangkan kerangka pemahaman akademis kewirausahaan maka inti kewirausahaan mencakup pengembangan dari universitas.

Akademis kewirausahaan dapat dikelompokkan ke dalam 4 area, yaitu: 1) atribut individu, 2) organisasi, 3) institusi, dan 4) aktivitas eksternal. Atribut individu diyakini sebagai refleksi tindakan individu sehingga akademis kewirausahaan merujuk pada personalitas individu dan kemampuankemampuan individu untuk memimpin aktivitas kewirausahaan. Determinan organisasi terkait dengan jenjang analisis organisasi serta pengaruhnya dari tekanantekanan lingkungan terhadap akademis kewirausahaan. Segmen ini menyelidiki aktivitas akademis kewirausahaan terhadap sumber-sumber universitas yang dapat diperoleh. Sumber-sumber tersebut mencakup pengeluaran di bidang riset dan pengembangan, eksistensi, terkemuka di dalam aktivitas riset, dan lembaga-lembaga transfer teknologi. Determinan institusi mengindikasikan aktivitas kewirausahaan yang lebih besar terjadi di universitasuniversitas yang memiliki lingkungan dalam merangkul aktivitas kewirausahaan. Lingkungan institusi dibentuk dari budaya universitas, norma sosial, sikap, dan perilaku dari anggota-anggota fakultas yang ada, sistem penghargaan terkait dengan penelitian dan publikasi, serta kebijakan dan prosedur transfer teknologi. Determinan eksternal terkait dengan akses untuk memperoleh sumber-sumber modal serta proksimitas kepada kelompok-kelompok teknologi tinggi.

Penelitian ini menggunakan model perilaku yang melibatkan integrasi individu, organisasi, dan institusi sebagai faktor-faktor determinan dan pengaruhnya terhadap academic entrepreneurial intention. Secara komprehensif model perilaku menempatkan 
academic entrepreneurial intention sebagai intervening varible yang mempengaruhi academic entrepreneurial behavior. Academic entrepreneurial intention dipengaruhi secara langsung oleh perceived desirability perceived feasibility, innovation values fit. Dan variabel-variabel tersebut secara tidak langsung berpengaruh terhadap academic entrepreneurial behavior. Model perilaku ini menguji bahwa lingkungan institusi yang positif akan mempengarruhi mempengaruhi intensi kewirausahaan individu di antara anggota-anggota komunitas universitas.

Dari latar belakang dan penjelasan mengenai model perilaku tersebut, rumusan masalah yang diajukan dalam penelitian ini adalah:

a. Apakah perceived desirability berpengaruh terhadap academic entrepreneurial intention?

b. Apakah perceived feasibility berpengaruh terhadap academic entrepreneurial intention?

c. Apakah innovation values fit berpengaruh terhadap academic entrepreneurial intention?

d. Apakah academic entrepreneurial intention berpengaruh terhadap academic entrepreneurial behavior?

e. Apakah perceived desirability berpengaruh terhadap academic entrepreneurial behavior melalui academic entrepreneurial intention?

f. Apakah perceived feasibility berpengaruh terhadap academic entrepreneurial behavior melalui academic entrepreneurial intention?

g. Apakah innovation values fit berpengaruh terhadap academic entrepreneurial behavior melalui academic entrepreneurial intention?

\section{TINJAUAN PUSTAKA}

\section{$2.1 \quad$ Penelitian Terdahulu}

Penelitian dengan topik serupa pernah dilakukan sebelumnya oleh Llano (2006). Dalam penelitian tersebut Llano mengkaji teori-teori yang sekiranya dapat membantu pemerintah, industri, dan universitas dalam mengidentifikasi faktorfaktor yang mempengaruhi perilaku entrepreneurial. Teori-teori yang dikaji dalam penelitian tersebut adalah Theory of Planned Behavior (Ajzen) Model berbasis intens terhadap kegiatan entrepreneurial (Shapero), dan Teori Penerapan Inovasi (Klein dan Sorra).

Hasil penemuan penelitian tersebut adalah ditemukannya model perilaku untuk mengukur kesuksesan universitas dan iklim akademis dalam menumbuhkan perilaku entrepreneurial. Model perilaku tersebut dalam penelitian ini digunakan sebagai model dasar penelitian serta pengaruhnya terhadap intens dan perilaku entrepreneurial di universitas khususnya di Surabaya.

\subsection{Perceived Desirability}

Pada umumnya, perspektif kewirausahaan menyangkut aktivitas kewirausahaan sebagai sebuah pilihan strategis organisasi. Manajemen menengah akan mempengaruhi aktivitas kewirausahaan organisasi, sebab memiliki tanggungjawab mengimplementasikan keputusan strategis dari manajemen puncak termasuk segala macam kegiatan yang ada.

Instrument-instrumen secara umum dari faktor-faktor lingkungan dalam hubungannya dengan literatur kewirausahaan mengungkapkan peranan fakor-faktor organisasi dalam mengukur Perceived Desirability (Cooper and Lucas, 2008; Dood et al., 2009) Jadi persepsi manajer menengah diidentifikasi dalam faktor-faktor yang mengarah pada aktivitas kewirausahaan. 


\subsection{Perceived Feasibility}

Kewirausahaan tidak terlepas dari kegagalan. Jadi untuk dapat mencapainya, memerlukan niat dan toleransi terhadap kegagalan. Perceived Feasibility merupakan system penghargaan dalam organisasi (Cooper and Lucas, 2008; Dood et al., 2009., Jose et al., 2011; Kelchen and Rab., 2012). Jadi suatu system yang mengacu pada pemberian penghargaan dan insentif untuk menggugah inspirasi perilaku kewirausahaan yang berdasarkan pada tujuan dan hasil.

\subsection{Innovation Values Fit}

Organisasi menyediakan sumbersumber berupa waktu, dana, sumber daya manusia, modal sosial, dan teknologi. Keberadaan struktur organisasi yang mendukung merupakan pendorong dari organisasi. Dengan demikian kesempatan untuk entrepreneurial terbuka lebar bagi anggota organisasi. Sebab harapan terhadap aktivitas entrepreneurial tidak akan terwujud manakala tidak ada dukungan dari organisasi (Teece, 2010; Schmiedgen, 2011; Dyer et al., 2008).

\subsection{Academic \\ Entrepreneurial Intention}

Academic Entrepreneurial Intention diumpamakan sebagai bangunan yang menghubungkan antara kesadaran kewirausahaan dengan perilaku kewirausahaan. Dapat diibaratkan sebagai pernyataan yang mengarahkan perhatian kea rah tujuan perilaku secara spesifik.

Academic Entrepreneurial Intention menggambarkan sebagai sebuah niat untuk penciptaan organisasi baru melalui proses pembelajaran entreneurial. Beberapa faktor penting di dalam Academic Entrepreneurial Intention, yaitu (Autio et al., 2001; Birkinshaw et al., 2008; Dyer et al., 2008; Erikson, 2004; Davidson, 1995; Schmiedgen, 2011; Teece, 2010; Nasurdin et al., 2009): a. Potensi Academic Entrepreneurial Intention yang terdapat di suatu universitas.

b. Pihak-pihak yang terlibat di universitas bersama-sama menggerakkan Academic Entrepreneurial Intention.

c. Lingkungan yang mempengaruhi kewirausahaan.

Jadi, apabila dalam sebuah universitas terdapat intens / niat entrepreneurial akan diikuti dengan pengembangan perilaku dan aktivitas entrepreneurial secara signifikan.

\subsection{Academic Entrepreneurial Behavior}

Pemahaman kewirausahaan dapat dikatakan menyangkut suatu kesempatan dari perspektif penemuan dan kesempatan dari perspektif penciptaan. Pandangan pertama Lebih menekankan bahwa kesempatan adalah tujuan, dimana kesempatan kesempatan berada disekitar lingkungan seseorang yang kemudian dengan kreativitas yang bersangkutan menemukan tujuan kesempatan. Dalam hal ini bantuan penggalian lebih dalam diperlukan dari rekan-rekan dalam kelompoknya. Sedangkan kesempatan perspektif penciptaan menyangkut pertukaran ide di antara rekan-rekan.

Dengan melihat uraian tersebut dapat dikatakan bahwa kewirausahaan adalah suatu kegiatan yang menyangkut penemuan, evaluasi, penggalian kesempatankesempatan untuk memperkenalkan produk dan jasa baru, cara-cara pengorganisasian pasar, pemrosesan, serta bahan-bahan melalui kemampuan organisasi yang belum pernah ada.

Beberapa asumsi tidak dapat dilepaskan begitu saja terutama yang terkait dengan masalah kewirausahaan (Dyer et al., 2008). Kewirausahaan mencakup semua aktivitas penemuan, mengevaluasi serta 
menggali kesempatan. Asumsi yang kedua adalah adanya keanekaragaman antar Individu, yang tampak pada pengalaman, akses sumber daya atau informasi,yang mana menyangkut proses kewirausahaan sampai berhasil meraih kesempatan tersebut. Sedangkan tiga asumsi lainnya adalah daya tahan terhadap resiko karena pertimbangan ketidakpastian, pengorganisasian dan inovasi.

\subsection{Hipotesis Penelitian}

Berdasarkan arah hubungan yang digambarkan dalam model, penelitian ini mengajukan tujuh hipotesis yang dirumuskan sebagai berikut:

a. Perceived desirability berpengaruh terhadap academic entrepreneurial intention.

b. Perceived feasibility berpengaruh terhadap academic entrepreneurial intention. c. Innovation values fit berpengaruh terhadap academic entrepreneurial intention.

d. Academic entrepreneurial intention berpengaruh terhadap academic entrepreneurial behavior.

e. Perceived desirability berpengaruh terhadap academic entrepreneurial behavior melalui academic entrepreneurial intention

f. Perceived feasibility berpengaruh terhadap academic entrepreneurial behavior melalui academic entrepreneurial intention.

g. Innovation values fit berpengaruh terhadap academic entrepreneurial behavior melalui academic entrepreneurial intention.

\subsection{Model Penelitian}

Berikut adalah model yang digunakan dalam penelitian ini (Gambar 1.).

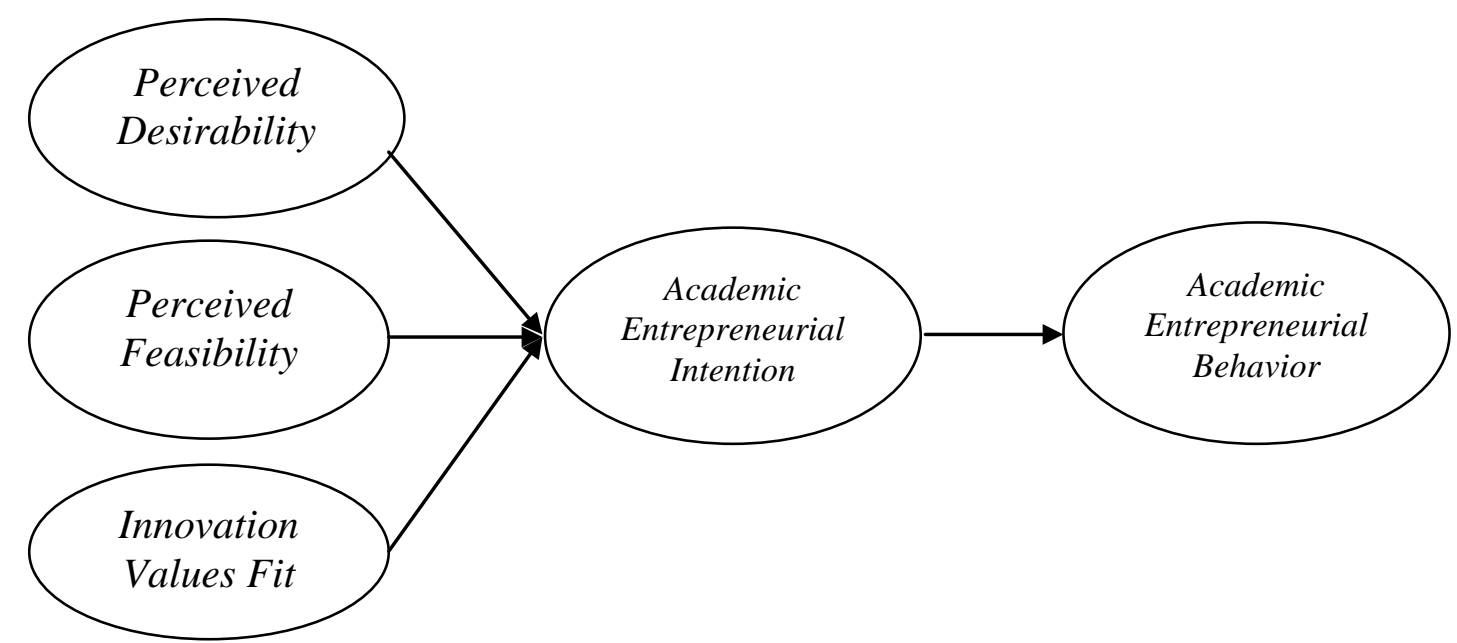

Gambar 1.

Model Penelitian

\section{METODE PENELITIAN}

\subsection{Desain Penelitian}

Pendekatan yang digunakan dalam penelitian ini adalah pendekatan penelitian kuantitatif. Pendekatan kuantitatif diterapkan karena dengan pendekatan ini proses penelitian dilakukan secara terstruktur dan menggunakan sampel penelitian dengan jumlah cukup besar yang dianggap mewakili 
populasi yang diteliti. Sampel yang digunakan dianggap dapat mewakili populasi yang diteliti sehingga hasil yang diperoleh dalam penelitian ini merupakan hasil yang konklusif bagi populasi darimana sampel penelitian diambil (Malhotra, 1993:93).

Penelitian ini dirancang dengan menggunakan hipotesis dan bersifat memberi penjelasan terhadap obyek yang diteliti (explanatory reseach). Dengan demikian, penelitian ini menyajikan penjelasan mengenai hubungan kausal antar variabel yang diteliti melalui pengujian hipotesis (Malhotra, 1993:102). Sementara itu, data yang dibutuhkan dalam penelitian ini adalah data primer yang diperoleh dengan menggunakan instrumen kuesioner.

Unit analisis dalam penelitian ini adalah mahasiswa Universitas Katolik Widya Mandala Surabaya. Dimensi waktu penelitian adalah cross sectional, yaitu penelitian dilangsungkan dalam waktu tertentu dengan menggunakan banyak responden (Malhotra, 1993:97).

Penelitian ini bertujuan untuk secara empirik membuktikan pengaruh: 1) perceived desirability terhadap academic entrepreneurial intention, 2) perceived feasibility terhadap academic entrepreneurial intention, 3) innovation values fit terhadap academic entrepreneurial intention, 4) perceived desirability terhadap academic entrepreneurial behavior melalui academic entrepreneurial intention, 5) perceived feasibility terhadap academic entrepreneurial behavior melalui academic entrepreneurial intention, 6) innovation values fit terhadap academic entrepreneurial behavior melalui academic entrepreneurial intention, dan 7) perceived desirability, perceived feasibility, dan innovation values fit terhadap academic entrepreneurial behavior melalui academic entrepreneurial intention. Untuk membuktikan pengaruh variabel-variabel yang diteliti tersebut, dalam penelitian ini digunakan Structural Equation Modeling (SEM).

\subsection{Identifikasi Variabel}

Kerangka konseptual dalam penelitian ini memiliki dua jenis variabel penelitian atau variabel konstruk (construct variable), yaitu: variabel eksogen dan variabel endogen. Identifikasi variabel dalam penelitian ini disajikan pada Tabel 1. berikut:

Tabel 1.

Identifikasi Variabel Penelitian

\begin{tabular}{|l|l||}
\hline \multicolumn{1}{|c|}{ VARIABEL } & \multicolumn{1}{c|}{ KLASIFIKASI } \\
\hline \hline Perceived desirability $\left(\mathrm{X}_{1}\right)$ & Variabel eksogen - independent variable \\
Perceived feasibility $\left(\mathrm{X}_{2}\right)$ & Variabel eksogen - independent variable \\
Innovation values fit $\left(\mathrm{X}_{3}\right)$ & Variabel eksogen - independent variable \\
Academic entrepreneurial intention $\left(\mathrm{Y}_{1}\right)$ & Variabel endogen - intervening variable intervening \\
Academic entrepreneurial behavior $\left(\mathrm{Y}_{2}\right)$ & Variabel endogen - dependent variable \\
\hline
\end{tabular}

Sumber : Data diolah

\subsection{Definisi Operasional Variabel}

Berikut adalah definisi operasional variable-variabel yang digunakan dalam penelitian ini : a. Perceived desirability $\left(\mathrm{X}_{1}\right)$

Perceived desirability $\left(\mathrm{X}_{1}\right)$ merupakan keinginan individu terhadap entrepreneurial yang dipersepsikan oleh seseorang. Variabel ini diukur dengan (Kennedy, et al., 2003): (1) Tertarik 
memulai bisnis sendiri, (2) Merasa senang memulai bisnis sendiri, (3) Merasa tegang memulai bisnis sendiri, dan (4) Antusias memulai bisnis sendiri.

b. Perceived feasibility $\left(\mathrm{X}_{2}\right)$

Perceived feasibility $\left(\mathrm{X}_{2}\right)$ merupakan kelayakan individu untuk menjadi entrepreneurial yang dipersepsikan oleh seseorang. Variabel ini diukur dengan (Kennedy, et al., 2003): (1) Memulai bisnis sendiri merupakan hal yang praktis, (2) Memulai bisnis sendiri merupakan hal yang mudah, (3) Memulai bisnis sendiri akan membuat sukses, dan (4) Memiliki pengetahuan yang cukup untuk memulai bisnis sendiri.

c. Innovation values fit $\left(\mathrm{X}_{3}\right)$

Innovation values fit $\left(\mathrm{X}_{3}\right)$ merupakan nilai-nilai untuk melakukan inovasi yang diyakini oleh seserang untuk menjadi entrepreneurial. Variabel ini diukur dengan

(https://innovation.govspace.gov.au): (1) Melalui entrepreneurial dapat menemukan, mengadaptasi atau menciptakan ide-ide, (2) Menerapkan ideide kedalam praktek entrepreneurial, (3) Menyebarkan ide-ide dan wawasan tentang entrepreneurial.

d. Academic entrepreneurial intention $\left(\mathrm{Y}_{1}\right)$ Academic entrepreneurial intention $\left(\mathrm{Y}_{1}\right)$ merupakan perhatian institusi pada entrepreneurial secara akademis untuk menjadi entrepreneurial yang dipersepsikan oleh mahasiswa di Surabaya. Variabel ini diukur dengan (Goethner, 2012): (1) Universitas menciptakan suasana kreatif yang menimbulkan inspirasi untuk mengembangkan ide-ide untuk memulai bisnis baru, (2) Universitas memberi pelatihan perencanaan bisnis dan kepemimpinan yang dibutuhkan untuk memulai bisnis baru, dan (3) Universitas memberi peluang dibentuknya tim mahasiswa multi disiplin untuk memulai bisnis baru.

e. Academic entrepreneurial behavior $\left(\mathrm{Y}_{2}\right)$ Academic entrepreneurial behavior $\left(\mathrm{Y}_{2}\right)$ merupakan perhatian institusi untuk menumbuhkan perilaku entrepreneurial secara akademis yang dipersepsikan oleh mahasiswa di Surabaya. Variabel ini diukur dengan (Goethner, 2012): (1) Universitas menawarkan kegiatan bagi mahasiswa untuk menemukan produk atau jasa baru yang dapat digunakan untuk memulai usaha, (2) Universitas melakukan evaluasi atas kegiatan bagi mahasiswa dalam menemukan produk atau jasa baru, dan (3) Universitas memberi kesempatan bagi mahasiswa untuk meningkatkan kemampuan dalam memulai usaha baru.

\subsection{Jenis dan Sumber Data}

Semua informasi yang dibutuhkan tentang variabel-variabel dalam penelitian ini disebut dengan data. Sumber data dalam penelitian ini adalah sumber data sekunder dan primer. Data sekunder berasal dari literatur untuk menyusun konseptual pemikiran sistematis dan mempertajam interpretasi setelah mengolah data primer. Jenis data yang diperoleh adalah data kualitatif.

Data primer merupakan semua data yang dikumpulkan secara langsung selama penelitian berlangsung melalui kuesioner. Untuk mendapatkan data primer, responden diminta mengisi kuesioner tersebut yang hasilnya adalah skor atas setiap jawaban responden terhadap masing-masing item pernyataan. Data primer yang dikumpulkan meliputi data mengenai Perceived desirability, Perceived feasibility, Innovation values fit, Academic entrepreneurial intention, dan Academic entrepreneurial behavior. Data tersebut diperoleh dari 
responden terpilih. Jenis data yang diperoleh adalah data kuantitatif.

\subsection{Pengukuran Data}

Skala yang digunakan dalam penelitian ini adalah Skala Likert interval 1 sampai dengan 5 dari sangat tidak setuju ke sangat setuju. Prosedur pembuatan Skala Likert adalah sebagai berikut (Nazir, 1998:397):

a. Peneliti mengumpulkan item-item yang relevan dengan masalah yang sedang diteliti.

b. Responden diminta memilih salah satu alternatif jawaban yang tersedia dari setiap item. Jawaban yang memberikan indikasi sangat menyetujui pernyataan yang diajukan di dalam item diberikan skor tertinggi, yaitu 5. Sebaliknya untuk jawaban yang memberikan indikasi sangat tidak menyetujui pernyataan yang diajukan di dalam item diberikan skor terendah, yaitu 1. Dengan kata lain skor yang diberikan untuk setiap item berkisar antara 1 sampai dengan 5 .

c. Total skor dari masing-masing responden adalah penjumlahan dari masing-masing item dari responden tersebut.

Langkah selanjutnya adalah menguji validitas dan reliabilitas instrumen mengingat bahwa rumusan-rumusan pernyataan dalam kuesioner dikembangkan sendiri oleh peneliti.

\subsection{Alat Pengumpulan Data}

Instrumen utama dalam penelitian ini adalah kuesioner. Kuesioner tersebut terdiri atas tiga bagian, yaitu:
a. Surat permohonan kesediaan untuk mengisi kuesioner.
b. Daftar pertanyaan mengenai karakteristik responden.
c. Daftar pernyataan yang menyangkut indikator-indikator Perceived desirability, Perceived feasibility, Innovation values

fit, Academic entrepreneurial intention, dan Academic entrepreneurial behavior.

\subsection{Validitas dan Realibilitas Alat Ukur}

Tahap ini merupakan suatu tahap dimana instrumen penelitian diuji-cobakan kepada sebagian kecil responden. Uji coba instrumen penelitian dilakukan untuk mendapatkan kepastian bahwa instrumen penelitian ini mengukur apa yang seharusnya diukur (valid) serta mengukur keakuratan dan konsistensi instrumen (reliable). Uji coba ini perlu ditempuh untuk menghindari kesalahan pengukuran pada saat disampaikan kepada responden yang sesungguhnya.

Uji validitas dalam penelitian ini dilakukan dengan mengukur korelasi antara skor indikator reflektif dengan skor variabel latennya. Untuk tujuan ini loading 0.5 sampai 0.6 dianggap cukup (Ghozali, 2008: 24; Solimun, 2008:78). Item pernyataan dapat dikatakan valid jika memiliki loading $\geq 0.5$.

Uji reliabilitas dalam penelitian ini dilakukan dengan mengukur korelasi antar jawaban pernyataan dalam kelompok indikator. walaupun bukan merupakan standar absolut, kelompok indikator yang mengukur sebuah variabel memiliki reliabilitas komposit yang baik jika mempunyai composite reliability $\geq 0.6$ (Solimun, 2008:79). Dengan kata lain item pernyataan dapat dikatakan reliabel jika memiliki composite reliability $\geq 0.6$.

\subsection{Populasi, Sampel, dan Teknik Pengambilan Sampel}

Populasi dalam penelitian ini adalah seluruh mahasiswa di Surabaya. Menurut Babbie (1986:176) sampel merupakan bagian khusus dari populasi yang diteliti. Semakin homogen populasi yang diteliti, semakin kecil besar sampel yang dibutuhkan. Sebaliknya semakin heterogen populasi yang 
diteliti, semakin besar ukuran sampel yang dibutuhkan. Menurut Nazir (1998:328) sampel adalah kumpulan dari unit sampling, yaitu unit yang membentuk basis dari proses sampling. Oleh karena itu karakteristik sampel dapat dinyatakan sebagai berikut:
a. Mahasiswa di Surabaya.
b. Berdomisili di Surabaya.
c. Berusia $>17$ tahun.

Mengingat bahwa dalam penelitian ini digunakan analisis SEM, maka besar sampel harus mengikuti aturan yang ada di dalam SEM. Apabila menggunakan alat analisis SEM, maka jumlah sampel minimal berkisar antara 100 sampai dengan 200 sampel. Penelitian ini menetapkan jumlah sampel terbesar yaitu 200 sampel. Penentuan sampel dalam penelitian ini dilakukan dengan random sampling technique, yaitu teknik pengambilan sampel yang memberi peluang yang sama bagi setiap unsur atau anggota populasi untuk dipilih menjadi sampel.

\subsection{Teknik Analisis Data}

Analisa data pada penelitian ini menggunakan uji Structural Equation Modelling (SEM). Namun sebelum dilakukan uji SEM ada asumsi yang perlu dipenuhi yaitu uji normalitas, outliers, multikolinearitas, dan singularitas.

\section{ANALISIS HASIL PENELITIAN}

\subsection{Hasil Deskripsi Responden}

Hasil karakteristik responden dapat dilihat pada Tabel 2. berikut ini.

Tabel 2.

Karakteristik Responden

\begin{tabular}{|l||c||c|}
\hline \multicolumn{1}{|c||}{ KARAKTERISTIK } & FREKUENSI & PERSENTASE (\%) \\
\hline \hline Mahasiswa di Surabaya & 200 & 100 \\
\hline \hline Berdomisili di Surabaya & 200 & 100 \\
\hline \hline Berusia $>17$ tahun & 200 & 100 \\
\hline
\end{tabular}

Sumber : Data diolah

Berdasarkan Tabel 2. dapat diketahui dari 200 responden yang ada, seluruh responden sudah memenuhi karakteristik sampel sebagaimana ditetapkan dalam penelitian ini.

\subsection{Statistik Deskriptif Variabel Penelitian}

Berdasarkan rentang nilai yang digunakan dalam penelitian, maka kelas frekuensi dapat dikelompokkan dalam Tabel 3. sebagai berikut. 
Tabel 3.

Kategori Penilaian Variabel Penelitian

\begin{tabular}{|c|c|}
\hline Interval Rata - Rata & Kategori \\
\hline \hline $1.0 \leq \mathrm{X}<1.8$ & Sangat Tidak Baik \\
\hline $1.8 \leq \mathrm{X}<2.6$ & Tidak Baik \\
\hline $2.6 \leq \mathrm{X}<3.4$ & Cukup \\
\hline \hline $3.4 \leq \mathrm{X}<4.2$ & Baik \\
\hline \hline $4.2 \leq \mathrm{X}<5.0$ & Sangat Baik \\
\hline
\end{tabular}

Sumber : Data diolah

\subsection{Statistik Deskriptif Perceived Desirability $\left(\mathrm{X}_{1}\right)$}

Tabel 4. menunjukkan bahwa pernyataan "Apabila saya memulai bisnis sendiri, saya akan melakukannya dengan senang hati” memiliki nilai rata-rata tertinggi yaitu sebesar 3.79, yang berarti responden memberikan penilaian mendekati sangat setuju. Sedangkan secara umum pernyataan variabel Perceived Desirability memiliki nilai rata-rata sebesar 3.58, yang berarti responden memberikan penilaian mendekati sangat setuju.

Tabel 4.

Statistik Deskriptif Perceived Desirability $\left(\mathrm{X}_{1}\right)$

\begin{tabular}{|c||c|c||}
\hline \multicolumn{1}{|c|}{ No. } & \multicolumn{1}{|c||}{ Pernyataan } & Rata-Rata \\
\hline \hline 1 & Saya tertarik untuk memulai bisnis sendiri & 3.65 \\
\hline \hline 2 & $\begin{array}{l}\text { Apabila saya memulai bisnis sendiri, saya akan melakukannya } \\
\text { dengan senang hati }\end{array}$ & 3.79 \\
\hline \hline 3 & Apabila saya memulai bisnis sendiri, saya akan merasa tegang. & 3.69 \\
\hline \hline 4 & $\begin{array}{l}\text { Apabila saya memulai bisnis sendiri, saya akan menjalaninya } \\
\text { dengan antusias }\end{array}$ & 3.19 \\
\hline \hline \multicolumn{2}{|l|}{ Rata-rata variabel Perceived Desirability } \\
\hline
\end{tabular}

Sumber : Data diolah

\subsection{Statistik Deskriptif Perceived Feasibility $\left(\mathrm{X}_{2}\right)$}

Tabel 5. menunjukkan bahwa pernyataan "Menurut saya, saya memiliki pengetahuan yang cukup untuk memulai bisnis sendiri" memiliki nilai rata-rata tertinggi yaitu sebesar 3.21, yang berarti responden memberikan penilaian mendekati setuju. Sedangkan secara umum pernyataan variabel Perceived Feasibility memiliki nilai rata-rata sebesar 3.16, yang berarti responden memberikan penilaian mendekati setuju. 
Tabel 5.

Statistik Deskriptif Perceived Feasibility $\left(\mathrm{X}_{2}\right)$

\begin{tabular}{|c|l|c|}
\hline \hline No. & \multicolumn{1}{|c|}{ Pernyataan } & Rata-Rata \\
\hline \hline 1 & Menurut saya, memulai bisnis sendiri merupakan hal yang praktis & 3.15 \\
\hline \hline 2 & Menurut saya, memulai bisnis sendiri merupakan hal yang mudah & 3.09 \\
\hline \hline 3 & Menurut saya, memulai bisnis sendiri akan membuat saya sukses & 3.19 \\
\hline 4 & $\begin{array}{l}\text { Menurut saya, saya memiliki pengetahuan yang cukup untuk } \\
\text { memulai bisnis sendiri }\end{array}$ & 3.21 \\
\hline \hline \multicolumn{2}{|l|}{ Rata-rata variabel Perceived Feasibility } & 3.16 \\
\hline
\end{tabular}

Sumber : Data diolah

\subsection{Statistik Deskriptif Innovation} Values Fit $\left(\mathrm{X}_{3}\right)$

Tabel 6. menunjukkan bahwa pernyataan "Menurut saya, saya dapat menyebarkan ide-ide dan wawasan tentang entrepreneurial" memiliki nilai rata-rata tertinggi yaitu sebesar 3.69, yang berarti responden memberikan penilaian mendekati setuju. Sedangkan secara umum pernyataan variable Innovation Values Fit memiliki nilai rata-rata sebesar 3.58, yang berarti responden memberikan penilaian mendekati setuju.

Tabel 6.

Statistik Deskriptif Innovation Values Fit $\left(\mathrm{X}_{3}\right)$

\begin{tabular}{|c|l|c||}
\hline No. & \multicolumn{1}{|c|}{ Pernyataan } & Rata-Rata \\
\hline \hline 1 & $\begin{array}{l}\text { Menurut saya, melalui entrepreneurial saya dapat menemukan, } \\
\text { mengadaptasi, atau menciptakan ide-ide. }\end{array}$ & 3.45 \\
\hline \hline 2 & $\begin{array}{l}\text { Menurut saya, saya dapat menerapkan ide-ide kedalam praktek } \\
\text { entrepreneurial. }\end{array}$ & 3.59 \\
\hline \hline 3 & $\begin{array}{l}\text { Menurut saya, saya dapat menyebarkan ide-ide dan wawasan } \\
\text { tentang entrepreneurial. }\end{array}$ & 3.69 \\
\hline \hline \multicolumn{2}{|l|}{ Rata-rata variabel Innovation Values Fit } & $\mathbf{3 . 5 8}$ \\
\hline
\end{tabular}

Sumber : Data diolah

\subsection{Statistik Deskriptif Academic Entrepreneurial Intention $\left(\mathbf{Y}_{1}\right)$}

Tabel 7. menunjukkan bahwa pernyataan "Menurut saya, universitas dimana saya belajar, memberi peluang dibentuknya tim mahasiswa multi disiplin untuk memulai bisnis baru" memiliki nilai rata-rata tertinggi yaitu sebesar 3.49, yang berarti responden memberikan penilaian mendekati setuju. Sedangkan secara umum pernyataan variable Academic Entrepreneurial Intention memiliki nilai rata-rata sebesar 3.39, yang berarti responden memberikan penilaian mendekati setuju. 
Tabel 7.

Statistik Deskriptif Academic Entrepreneurial Intention ( $\left.\mathrm{Y}_{1}\right)$

\begin{tabular}{|c||l|c||}
\hline \multicolumn{1}{|c||}{ No. } & \multicolumn{1}{|c||}{ Pernyataan } & Rata-Rata \\
\hline \hline 1 & $\begin{array}{l}\text { Menurut saya, universitas dimana saya belajar, menciptakan } \\
\text { suasana kreatif yang menimbulkan inspirasi bagi saya untuk } \\
\text { mengembangkan ide-ide untuk } \\
\text { memulai bisnis baru }\end{array}$ & 3.45 \\
\hline \hline 2 & $\begin{array}{l}\text { Menurut saya, universitas dimana saya belajar, memberi pelatihan } \\
\text { perencanaan bisnis dan kepemimpinan yang saya butuhkan untuk } \\
\text { memulai bisnis baru }\end{array}$ & 3.23 \\
\hline \hline 3 & $\begin{array}{l}\text { Menurut saya, universitas dimana saya belajar, memberi peluang } \\
\text { dibentuknya tim mahasiswa multi disiplin untuk memulai bisnis } \\
\text { baru }\end{array}$ & 3.49 \\
\hline \hline Rata-rata variabel Academic Entrepreneurial Intention & $\mathbf{3 . 3 9}$ \\
\hline
\end{tabular}

Sumber : Data diolah

\subsection{Statistik Deskriptif Academic Entrepreneurial Behavior $\left(\mathrm{Y}_{2}\right)$}

Tabel 8. menunjukkan bahwa pernyataan "Menurut saya, universitas dimana saya belajar, memberi kesempatan bagi mahasiswa untuk meningkatkan kemampuan dalam memulai usaha baru" memiliki nilai rata-rata tertinggi yaitu sebesar 3.39, yang berarti responden memberikan penilaian mendekati setuju. Sedangkan secara umum pernyataan variable Academic Entrepreneurial Behavior memiliki nilai rata-rata sebesar 3.36, yang berarti responden memberikan penilaian mendekati setuju.

Tabel 8.

Statistik Deskriptif Academic Entrepreneurial Behavior $\left(\mathrm{Y}_{2}\right)$

\begin{tabular}{|c||l||c||}
\hline \hline No & \multicolumn{1}{|c||}{ Pernyataan } & Rata-Rata \\
\hline \hline 1 & $\begin{array}{l}\text { Menurut saya, universitas dimana saya belajar, menawarkan } \\
\text { kegiatan bagi mahasiswa untuk menemukan produk atau jasa baru } \\
\text { yang dapat digunakan untuk memulai usaha }\end{array}$ & 3.45 \\
\hline \hline 2 & $\begin{array}{l}\text { Menurut saya, universitas dimana saya belajar, melakukan evaluasi } \\
\text { atas kegiatan bagi mahasiswa dalam menemukan produk atau jasa } \\
\text { baru }\end{array}$ & 3.23 \\
\hline \hline 3 & $\begin{array}{l}\text { Menurut saya, universitas dimana saya belajar, memberi } \\
\text { kesempatan bagi mahasiswa untuk meningkatkan kemampuan } \\
\text { dalam memulai usaha baru }\end{array}$ & 3.39 \\
\hline \hline Rata-rata variabel Academic Entrepreneurial Behavior & 3.36 \\
\hline
\end{tabular}

Sumber : Data diolah

\subsection{Uji Validitas dan Reliabilitas}

Tabel 9. membuktikan bahwa

kuesioner yang digunakan untuk penggalian data dalam penelitian dinyatakan sepenuhnya valid dan reliabel, sehingga olah data dapat dilanjutkan. 
Tabel 9.

Uji Validitas dan Reliabitas

\begin{tabular}{|c|c|c|c|}
\hline PENGARUH & ESTIMATE & $p$ & RELIABILITAS \\
\hline $\mathrm{X}_{1.1} \rightarrow \mathrm{X}_{1}$ & .785 & $* * *$ & \multirow{4}{*}{0.861} \\
\hline $\mathrm{X}_{1.2} \rightarrow \mathrm{X}_{1}$ & .856 & **** & \\
\hline $\mathrm{X}_{1.3} \rightarrow \mathrm{X}_{1}$ & .860 & $* * *$ & \\
\hline $\mathrm{X}_{1.4} \rightarrow \mathrm{X}_{1}$ & .743 & $* * *$ & \\
\hline $\mathrm{X}_{2.1} \rightarrow \mathrm{X}_{2}$ & .689 & $* * *$ & \multirow{4}{*}{0.887} \\
\hline $\mathrm{X}_{2.2} \rightarrow \mathrm{X}_{2}$ & .765 & $* * *$ & \\
\hline $\mathrm{X}_{2.3} \rightarrow \mathrm{X}_{2}$ & .813 & *** & \\
\hline $\mathrm{X}_{2.4} \rightarrow \mathrm{X}_{2}$ & .974 & *** & \\
\hline $\mathrm{X}_{3.1} \rightarrow \mathrm{X}_{3}$ & .892 & $* * *$ & \multirow{3}{*}{0.951} \\
\hline $\mathrm{X}_{3.2} \rightarrow \mathrm{X}_{3}$ & .937 & **** & \\
\hline $\mathrm{X}_{3.3} \rightarrow \mathrm{X}_{3}$ & .928 & **** & \\
\hline $\mathrm{Y}_{1.1} \rightarrow \mathrm{Y}_{1}$ & .679 & $* * *$ & \multirow{3}{*}{0.836} \\
\hline $\mathrm{Y}_{1.2} \rightarrow \mathrm{Y}_{1}$ & .746 & **** & \\
\hline $\mathrm{Y}_{1.3} \rightarrow \mathrm{Y}_{1}$ & .958 & $* * *$ & \\
\hline $\mathrm{Y}_{2.1} \rightarrow \mathrm{Y}_{2}$ & .781 & $* * *$ & \multirow{3}{*}{0.889} \\
\hline $\mathrm{Y}_{2.2} \rightarrow \mathrm{Y}_{2}$ & .827 & $* * *$ & \\
\hline $\mathrm{P}_{2.3} \rightarrow \mathrm{Y}_{2}$ & .967 & **** & \\
\hline
\end{tabular}

Sumber : Data diolah

\subsection{Uji Asumsi SEM}

\subsubsection{Uji Normalitas}

Hasil secara lengkap mengenai pengujian normalitas data pada seluruh variabel penelitian menunjukkan hasil sebesar 1.904 dan nilai ini terletak diantara 1.96 sampai dengan 1.96, sehingga dapat dikatakan bahwa data terdistribusi dengan normal.

\subsubsection{Uji Singularitas}

Hasil penelitian memberikan nilai determinant of sample covariance matrix sebesar 0,4. Nilai ini tidak sama dengan nol sehingga dapat dikatakan bahwa tidak terdapat masalah singularitas pada data yang dianalisis.

\subsubsection{Outlier}

Hasil uji outlier pada penelitian ini membuktikan tidak ada nilai data yang menunjukkan adanya outlier.

\subsection{Uji Goodness Of Fit}

Tabel 10. menunjukkan bahwa 8 kriteria yang digunakan untuk menilai Goodness Of Fit membuktikan bahwa model penelitian adalah baik. 
Tabel 10.

Uji Goodness Of Fit

\begin{tabular}{|l|c||c|c||}
\hline Kriteria & Nilai Cut - Off & Hasil Perhitungan & Keterangan \\
\hline \hline Chi - Square & Diharapkan kecil & 357.190 & Cukup Baik \\
\hline \hline Significance Probability & $\geq 0.05$ & 0.098 & Cukup Baik \\
\hline \hline RMSEA & $\leq 0.08$ & 0.016 & Baik \\
\hline \hline GFI & $\geq 0.90$ & 0.962 & Baik \\
\hline \hline AGFI & $\geq 0.90$ & 0.950 & Baik \\
\hline \hline CMIN/DF & $\leq 2.00$ & 1.355 & Baik \\
\hline \hline TLI & $\geq 0.95$ & 0.990 & Baik \\
\hline \hline CFI & $\geq 0.95$ & 0.953 & Baik \\
\hline
\end{tabular}

Sumber : Data diolah

\subsection{Persamaan Regresi}

Hasil penelitian menghasilkan persamaan struktural sebagai berikut:

$\mathrm{Y}_{1}=0.157 \mathrm{X}_{1}+0.211 \mathrm{X}_{2}+0.647 \mathrm{X}_{3}$ $\mathrm{Y}_{2}=0.828 \mathrm{Y}_{1}$

Persamaan tersebut membuktikan bahwa sifat pengaruh antar variabel adalah positif. Artinya bahwa, apabila variabel eksogen naik maka variabel endogen juga akan naik mengikuti pergerakan arah variabel eksogen.

\subsection{Uji Hipotesis}

Hasil uji hipotesis dapat dilihat pada Tabel 11. di bawah ini.

Tabel 11.

Uji Hipotesis

\begin{tabular}{|c|c|c|c|}
\hline Variabel & Koefisien & Prob. & Keterangan \\
\hline $\begin{array}{l}\text { Perceived Desirability }\left(\mathrm{X}_{1}\right) \rightarrow \\
\text { Academic Entrepreneurial Intention }\left(\mathrm{Y}_{1}\right)\end{array}$ & 0.517 & 0.008 & Signifikan \\
\hline $\begin{array}{l}\text { Perceived Feasibility }\left(\mathrm{X}_{2}\right) \rightarrow \\
\text { Academic Entrepreneurial Intention }\left(\mathrm{Y}_{1}\right)\end{array}$ & 0.712 & 0.000 & Signifikan \\
\hline $\begin{array}{l}\text { Innovation Values Fit }\left(\mathrm{X}_{3}\right) \rightarrow \\
\text { Academic Entrepreneurial Intention }\left(\mathrm{Y}_{1}\right)\end{array}$ & 0.647 & 0.000 & Signifikan \\
\hline $\begin{array}{l}\text { Academic Entrepreneurial Intention }\left(\mathrm{Y}_{1}\right) \rightarrow \text { Academic } \\
\text { Entrepreneurial Behavior }\left(\mathrm{Y}_{2}\right)\end{array}$ & 0.832 & 0.001 & Signifikan \\
\hline $\begin{array}{l}\text { Perceived Desirability }\left(\mathrm{X}_{1}\right) \rightarrow \\
\text { Academic Entrepreneurial Intention }\left(\mathrm{Y}_{1}\right) \rightarrow \text { Academic } \\
\text { Entrepreneurial Behavior }\left(\mathrm{Y}_{2}\right)\end{array}$ & 0.430 & 0.000 & Signifikan \\
\hline $\begin{array}{l}\text { Perceived Feasibility }\left(\mathrm{X}_{2}\right) \rightarrow \\
\text { Academic Entrepreneurial Intention }\left(\mathrm{Y}_{1}\right) \rightarrow \text { Academic } \\
\text { Entrepreneurial Behavior }\left(\mathrm{Y}_{2}\right)\end{array}$ & 0.592 & 0.000 & Signifikan \\
\hline $\begin{array}{l}\text { Innovation Values Fit }\left(\mathrm{X}_{3}\right) \rightarrow \\
\text { Academic Entrepreneurial Intention }\left(\mathrm{Y}_{1}\right) \rightarrow \text { Academic } \\
\text { Entrepreneurial Behavior }\left(\mathrm{Y}_{2}\right)\end{array}$ & 0.538 & 0.000 & Signifikan \\
\hline
\end{tabular}

Sumber : Data diolah 
Berdasarkan Tabel 11. interpretasi masing-masing koefisien jalur adalah sebagai berikut:

a. Perceived desirability $\left(\mathrm{X}_{1}\right)$ berpengaruh positif dan signifikan terhadap Academic Entrepreneurial Intention ( $\left.\mathrm{Y}_{1}\right)$. Hal ini dibuktikan dari persamaan struktural bertanda positif dan sebesar 0.517 dengan probabilitas signifikansi (p) sebesar 0.008 yang lebih kecil dari taraf signifikansi $(\alpha)$ ditentukan sebesar 0.05. Dengan kata lain, setiap kenaikan Perceived desirability $\left(\mathrm{X}_{1}\right)$ maka akan meningkatkan Academic Entrepreneurial Intention $\left(\mathrm{Y}_{1}\right)$.

b. Perceived Feasibility $\left(\mathrm{X}_{2}\right)$ berpengaruh positif dan signifikan terhadap Academic Entrepreneurial Intention $\left(\mathrm{Y}_{1}\right)$. Hal ini dibuktikan dari persamaan struktural bertanda positif sebesar 0.712 dengan probabilitas signifikansi (p) sebesar 0.000 yang lebih kecil dari taraf signifikansi $(\alpha)$ ditentukan sebesar 0.05. Dengan kata lain setiap kenaikan Perceived Feasibility $\left(\mathrm{X}_{2}\right)$ maka akan meningkatkan Academic Entrepreneurial Intention $\left(\mathrm{Y}_{1}\right)$.

c. Innovation Values Fit $\left(\mathrm{X}_{3}\right)$ berpengaruh positif dan signifikan terhadap Academic Entrepreneurial Intention $\left(\mathrm{Y}_{1}\right)$. Hal ini dibuktikan dari persamaan struktural bertanda positif sebesar 0.647 dengan probabilitas signifikansi (p) sebesar 0.000 yang lebih kecil dari taraf signifikansi $(\alpha)$ ditentukan sebesar 0.05. Dengan kata lain setiap kenaikan Innovation Values Fit $\left(\mathrm{X}_{3}\right)$ maka akan meningkatkan Academic Entrepreneurial Intention $\left(\mathrm{Y}_{1}\right)$.

d. Academic Entrepreneurial Intention $\left(\mathrm{Y}_{1}\right)$ berpengaruh positif dan signifikan terhadap Academic Entrepreneurial Behavior $\left(\mathrm{Y}_{2}\right)$. Hal ini dibuktikan dari persamaan struktural bertanda positif sebesar 0.832 dengan probabilitas signifikansi (p) sebesar 0.000 yang lebih kecil dari taraf signifikansi $(\alpha)$ ditentukan sebesar 0.05. Dengan kata lain setiap kenaikan Academic Entrepreneurial Intention $\left(\mathrm{Y}_{1}\right)$ maka akan meningkatkan Academic Entrepreneurial Behavior $\left(\mathrm{Y}_{2}\right)$.

e. Perceived desirability $\left(\mathrm{X}_{1}\right)$ berpengaruh positif dan signifikan terhadap Academic Entrepreneurial Behavior $\left(\mathrm{Y}_{2}\right)$ melalui Academic Entrepreneurial Intention $\left(\mathrm{Y}_{1}\right)$. Hal ini dibuktikan dari persamaan struktural bertanda positif sebesar 0.310 dengan probabilitas signifikansi (p) sebesar 0.000 yang lebih kecil dari taraf signifikansi $(\alpha)$ ditentukan sebesar 0.05 . Dengan kata lain setiap kenaikan Perceived desirability $\left(\mathrm{X}_{1}\right)$ akan meningkatkan Academic Entrepreneurial Behavior $\left(\mathrm{Y}_{2}\right)$ melalui Academic Entrepreneurial Intention $\left(\mathrm{Y}_{1}\right)$.

f. Perceived Feasibility $\left(\mathrm{X}_{2}\right)$ berpengaruh positif dan signifikan terhadap Academic Entrepreneurial Behavior $\left(\mathrm{Y}_{2}\right)$ melalui Academic Entrepreneurial Intention $\left(\mathrm{Y}_{1}\right)$. Hal ini dibuktikan dari persamaan struktural bertanda positif sebesar 0.741 dengan probabilitas signifikansi (p) sebesar 0.000 yang lebih kecil dari taraf signifikansi $(\alpha)$ ditentukan sebesar 0.05 . Dengan kata lain setiap kenaikan Perceived Feasibility $\left(\mathrm{X}_{2}\right)$, Academic Entrepreneurial Intention $\left(\mathrm{Y}_{1}\right)$ akan meningkatkan Academic Entrepreneurial Behavior $\left(\mathrm{Y}_{2}\right)$ melalui Academic Entrepreneurial Intention $\left(\mathrm{Y}_{1}\right)$.

g. Innovation Values Fit $\left(\mathrm{X}_{3}\right)$ berpengaruh positif dan signifikan terhadap Academic Entrepreneurial Behavior $\left(\mathrm{Y}_{2}\right)$ melalui Academic Entrepreneurial Intention $\left(\mathrm{Y}_{1}\right)$. Hal ini dibuktikan dari persamaan struktural bertanda positif sebesar 0.653 dengan probabilitas signifikansi (p) sebesar 0.000 yang lebih kecil dari taraf signifikansi $(\alpha)$ ditentukan sebesar 0.05 . Dengan kata lain setiap kenaikan Innovation Values Fit $\left(\mathrm{X}_{3}\right)$ akan meningkatkan Academic Entrepreneurial 
Behavior $\left(\mathrm{Y}_{2}\right)$ melalui Academic Entrepreneurial Intention $\left(\mathrm{Y}_{1}\right)$.

\section{PEMBAHASAN}

\subsection{Perceived desirability berpengaruh terhadap academic entrepreneurial intention}

Hipotesis pertama dalam penelitian ini perceived desirability berpengaruh terhadap academic entrepreneurial intention diterima. Berdasarkan hasil statistik deskriptif, jawaban responden paling tinggi untuk variabel perceived desirability adalah apabila saya memulai bisnis sendiri, saya akan melakukannya dengan senang hati disetujui oleh responden. Hal ini dapat diartikan bahwa responden akan menjalankan bisnis sendiri dengan senang hati.

Hasil penelitin ini juga membuktikan bahwa perceived desirability memiliki pengaruh positif dan signifikan terhadap academic entrepreneurial intention. Hasil penelitian ini mendukung penelitian yang telah dilakukan sebelumnya oleh Llano (2006) juga mendukung Teori Shapero and Sokol (1982); Hout et al., (1999); Blanchflower et al., (2007); White et al., (2007); Krueger (1993); Krueger et al., (2000) dalam Wang et al., yang menyatakan bahwa perceived desirability berpengaruh terhadap academic entrepreneurial intention.

\subsection{Perceived feasibility berpengaruh terhadap academic entrepreneurial intention \\ Hipotesis kedua dalam penelitian ini} perceived feasibility berpengaruh terhadap academic entrepreneurial intention diterima. Berdasarkan hasil statistik deskriptif, jawaban responden paling tinggi untuk variabel perceived feasibility adalah menurut saya, saya memiliki pengetahuan yang cukup untuk memulai bisnis sendiri disetujui oleh responden. Hal ini dapat diartikan bahwa responden memiliki pengetahuan yang cukup untuk menjalankan bisnis sendiri.

Hasil penelitin ini juga membuktikan bahwa perceived feasibility memiliki pengaruh positif dan signifikan terhadap academic entrepreneurial intention. Hasil penelitian ini mendukung penelitian yang telah dilakukan sebelumnya oleh Llano (2006) juga mendukung Teori Shapero and Sokol (1982); Hout et al., (1999); Blanchflower et al., (2007); White et al., (2007); Krueger (1993); Krueger et al., (2000) dalam Wang et al., yang menyatakan bahwa perceived feasibility berpengaruh terhadap academic entrepreneurial intention.

\subsection{Innovation values fit berpengaruh terhadap academic entrepreneurial intention}

Hipotesis ketiga dalam penelitian ini innovation values fit berpengaruh terhadap academic entrepreneurial intention diterima. Berdasarkan hasil statistik deskriptif, jawaban responden paling tinggi untuk variabel innovation values fit adalah menurut saya, saya dapat menyebarkan ide-ide dan wawasan tentang entrepreneurial disetujui oleh responden. Hal ini dapat diartikan bahwa responden memiliki kemampuan untuk menyebarkan gagasan dan wawasan tentang entrepreneurial.

Hasil penelitin ini juga membuktikan bahwa innovation values fit memiliki pengaruh positif dan signifikan terhadap academic entrepreneurial intention. Hasil penelitian ini mendukung penelitian yang telah dilakukan sebelumnya oleh Llano (2006) juga mendukung Teori Shapero and Sokol (1982); Hout et al., (1999); Blanchflower et al., (2007); White et al., (2007); Krueger (1993); Krueger et al., (2000) dalam Wang et al., yang menyatakan bahwa innovation values fit berpengaruh terhadap academic entrepreneurial intention. 


\subsection{Academic entrepreneurial intention} berpengaruh terhadap academic entrepreneurial behavior

Hipotesis keempat dalam penelitian ini academic entrepreneurial intention berpengaruh terhadap academic entrepreneurial behavior diterima. Berdasarkan hasil statistik deskriptif, jawaban responden paling tinggi untuk variabel perceived feasibility adalah menurut saya, universitas dimana saya belajar, memberi peluang dibentuknya tim mahasiswa multi disiplin untuk memulai bisnis baru disetujui oleh responden. Hal ini dapat diartikan bahwa responden merasakan peluang dibentuknya tim mahasiswa multi disiplin untuk memulai bisnis baru yang diberikan oleh universitas.

Hasil penelitin ini juga membuktikan bahwa academic entrepreneurial intention memiliki pengaruh positif dan signifikan terhadap academic entrepreneurial behavior. Hasil penelitian ini mendukung penelitian yang telah dilakukan sebelumnya oleh Llano (2006) juga mendukung Teori Shapero and Sokol (1982); Hout et al., (1999); Blanchflower et al., (2007); White et al., (2007); Krueger (1993); Krueger et al., (2000) dalam Wang et al., yang menyatakan bahwa academic entrepreneurial intention berpengaruh terhadap academic entrepreneurial behavior.

\subsection{Perceived desirability berpengaruh terhadap academic entrepreneurial behavior melalui academic entrepreneurial intention}

Hipotesis kelima dalam penelitian ini perceived desirability berpengaruh terhadap academic entrepreneurial behavior melalui academic entrepreneurial intention diterima. Berdasarkan hasil statistik deskriptif, jawaban responden paling tinggi untuk variabel academic entrepreneurial behavior adalah menurut saya, universitas dimana saya belajar, memberi kesempatan bagi mahasiswa untuk meningkatkan kemampuan dalam memulai usaha baru disetujui oleh responden. Hal ini dapat diartikan bahwa responden merasakan bahwa universitas memberi kesempatan bagi mahasiswa untuk meningkatkan kemampuan dalam memulai usaha baru kesempatan bagi mahasiswa untuk meningkatkan kemampuan dalam memulai usaha baru.

Hasil penelitin ini juga membuktikan bahwa perceived desirability memiliki pengaruh positif dan signifikan terhadap academic entrepreneurial behavior melalui academic entrepreneurial intention. Hasil penelitian ini mendukung penelitian yang telah dilakukan sebelumnya oleh Llano (2006).

\subsection{Perceived feasibility berpengaruh terhadap academic entrepreneurial behavior melalui academic entrepreneurial intention \\ Hipotesis keenam dalam penelitian} ini perceived feasibility berpengaruh terhadap academic entrepreneurial behavior melalui academic entrepreneurial intention diterima.

Hasil penelitin ini juga membuktikan bahwa perceived feasibility memiliki pengaruh positif dan signifikan terhadap academic entrepreneurial behavior melalui academic entrepreneurial intention. Hasil penelitian ini mendukung penelitian yang telah dilakukan sebelumnya oleh Llano (2006).

\subsection{Innovation values fit berpengaruh terhadap academic entrepreneurial behavior melalui academic entrepreneurial intention}

Hipotesis ketujuh dalam penelitian ini innovation values fit berpengaruh terhadap academic entrepreneurial behavior 
melalui academic entrepreneurial intention diterima.

Hasil penelitin ini juga membuktikan bahwa innovation values fit memiliki pengaruh positif dan signifikan terhadap academic entrepreneurial behavior melalui academic entrepreneurial intention. Hasil penelitian ini mendukung penelitian yang telah dilakukan sebelumnya oleh Llano (2006).

\section{KESIMPULAN DAN SARAN}

\subsection{Kesimpulan}

Kesimpulan yang dapat diambil dari hasil penelitian ini adalah:

a. Hipotesis 1 yang menyatakan perceived desirability berpengaruh terhadap academic entrepreneurial intention diterima.

b. Hipotesis 2 yang menyatakan perceived feasibility berpengaruh terhadap academic entrepreneurial intention diterima.

c. Hipotesis 3 yang menyatakan innovation values fit berpengaruh terhadap academic entrepreneurial intention diterima.

d. Hipotesis 4 yang menyatakan academic entrepreneurial intention berpengaruh terhadap academic entrepreneurial behavior diterima.

e. Hipotesis 5 yang menyatakan perceived desirability berpengaruh terhadap academic entrepreneurial behavior melalui academic entrepreneurial intention diterima.

f. Hipotesis 6 yang menyatakan perceived feasibility berpengaruh terhadap academic entrepreneurial behavior melalui academic entrepreneurial intention diterima.

g. Hipotesis 7 yang menyatakan innovation values fit berpengaruh terhadap academic entrepreneurial behavior melalui academic entrepreneurial intention diterima.

\subsection{Saran}

Penelitian yang akan datang dalam rangka menindaklanjuti penelitian ini diharapkan dapat menguji Theory Reason Action dan Theory Planned Behavior. Usulan ini berlandaskan pada kajian atas beberapa pengukuran yang digunakan dalam menggali data pada penelitian ini yang mengindikasikan adanya sikap, kepercayaan, dan niat berperilaku baik dari universitas maupun dari mahasiswa di bidang entrepreneurial.

Universitas hendaknya membangun iklim entrepreneurial secara sistemik. Tidak hanya member peluang bagi mahasiswa saja, namun juga menyiapkan kurikulum lintas disiplin ilmu, teknologi, dana, waktu, dan sumber daya manusia yang kompeten.

Mahasiswa hendaknya mengevaluasi kekuatan dan kelemahan diri sebelum masuk di bidang entrepreneurial. Karena hasil penelitian ini membuktikan bahwa kepercayaan diri, pengetahuan, dan daya juang berpengaruh signifikan terhadap niat berperilaku dalam bidang entrepreneurial. 


\section{DAFTAR PUSTAKA}

Autio, Erkko, Robert H. Keeley, Magnus Klofsten, George G.C. Parker, dan Michael Hay. 2001. "Entrepreneurial Intent Among Students in Scandinavia and in the USA". Enterprise and Innovation Management Studies, Vol 2, No 2, 145-160.

Babbie, E. 1986. The Practice of Social Research, Fourth Edition, United State of America: Wadsworth Inc.

Birkinshaw, Julian, Gary Hamel dan Michael J. Mol. 2008. "Management innovation". Academy of Management Review, Vol 33, No 4, 825-845.

Cooper, Sarah dan William L. 2008. "Exploring The Role Of Education In Influencing Perceived desirability, Feasibility and Intentions Towards Entreprenurship” AGSE, 53-65.

Davidsson, Per. 1995. "Determinants Of Entrepreneurial Intentions". Jonkoping International Business School (JIBS), Nov 23-24, 1-31.

Dodd, Drakopoulou Sarah, Alexis Komselis dan Joseph Hassid. 2009. "The Comparative Perceived Desirability and Feasibility Of Entrepreneurship Within Greek Schools”. University of Piraeus, Vol 59, No 1-2, 38-56.

Dyer, H Jeffrey, Hal B Gregersen dan Clayton Christensen. 2008. "Entrepreneur Behaviors, Opportunity Recognition, and the Origins of Innovative Ventures". Strategic Entrepreneurship Journal, No 2, 317-338.

Erikson, Y Truls. 2004. "A Study Of Entrepreneurial Intentions among A Cohort MBAS - The Extended Bird Model”. ICSB World Conference, 1-12.

Ghozali, Imam. 2008. Structural Equation Modeling PLS, Edisi 2, Semarang: Badan Penerbit Universitas Diponegoro.

https://innovation.govspace.gov.au

Jose, A. Garrido, Zamarreno Teofilo, Giron Sara, Ruiz Padillo, Diego. 2011. "Perceived Feasibility Of Computer-Generated Auralization In Concert Halls” International Seminar on Virtual Acoustics, November 24-25, 153-162.

Kelchen, Robert dan Sara Goldrick Rab. 2012. Accelerating College Knowledge: Examining the Feasibility of a targeted early Commitment Pell Grant Program, 1-48.

Kennedy, Jessica, Judy Drennan, Patty Renfrow, dan Bernadette Watson. 2003. "Situational Factors and Entrepreneurial Intentions”. 16th Annual Conference of Small Enterprise Association of Australia and New Zealand, 28 September - 1 Oktober, 1-12.

Lorz, Michael. 2011. “The impact of Entrepreneurship Education on Entreprenurial Intention”. Dissertation, The University of St Gallen.

Llano, Joseph Anthony. 2006. The University Environment and Academic entrepreneurship: A Behavioral Model For Measuring Environment Success, Hoboken, New Jersey, Stevens Institute of Technology.

Malhotra, K Naresh. 1993. Marketing Research: An Apllied Orientation, New Jersey: Englewood Cliffs.

Nasurdin, Mohd Aizzat, Noor Hazlina Ahmad, Chew Ee Lin. 2009. "Examining a Model of Entrepreneurial Intention Among Malaysians Using SEM Procedure”. European Journal of Scientific Research, Vol 33, No 2, 365-373.

Nazir, Mohammad. 1998. Metode Penelitian, Cetakan 3, Jakarta: Ghalia Indonesia.

Schmiedgen, jan. 2011. "Innovating User Value”. Thesis, Zeppelin University, Berlin.

Teece, J. David. 2010. “Business Models, Business Strategy and Innovation”. Elsevier, No 43, 172-194.

Wang, Wenjun, Wei Lu, dan John Kent Millington. 2011. "Determinants of Entrepreneurial Intention among College Students in China and USA". Journal of Global Entrepreneurship Research, Winter \& Spring, 2011, Vol.1, No.1, 35-44.

www.tempointeraktif.com, 10 Nopember 2012.

www.ditkelembagaan, 10 Nopember 2012. 